\title{
On the spectrum of oxygen, and on the electrical luminous phenomena of rarefied gases in tubes with liquid electrodes
}

\section{Paalzow}

To cite this article: M. Paalzow (1879) On the spectrum of oxygen, and on the electrical luminous phenomena of rarefied gases in tubes with liquid electrodes, Philosophical Magazine Series 5, 7:43, 297-300, DOI: 10.1080/14786447908639609

To link to this article: http://dx.doi.org/10.1080/14786447908639609

曲 Published online: 13 May 2009.

Submit your article to this journal $\pi$

Џll Article views: 2

Q View related articles $\sqsubset$ 
The motion of diffusion has two properties in common with wave-motion, which follow from the linear form of the differential equations determining the laws of these motions. The first is the superposition of the diffusion-currents which start from different parts of the liquid; the second is the complete reffection which the diffusion-currents undergo at the boundaries of the liquid. Both properties can with great advantage be made use of in the calculation of Tables. The memoir contains also a formula, based on them, which permits the diffusion-coefficient to be calculated in a very simple way from a combination of the salt-contents of the individual layers.

As regards the amount of these coefficients $k$, inter alia there were found :-

$$
\begin{aligned}
& \text { For Caramel (temp. } 10^{\circ} \text { ) . . . . k } k=0.047 \\
& \text { Albumen }\left(13^{\circ}\right) \ldots \ldots \ldots, k=0 \cdot 063 \\
& \text { Cane-sugar }\left(9^{\circ}\right) \ldots \ldots \ldots, k=0.312 \\
& \text { Chloride of sodium }\left(5^{\circ}\right) \ldots k=0.765 \\
& \text { Hydrochloric acid }\left(5^{\circ}\right) \ldots \ldots k=1 \cdot 742
\end{aligned}
$$

and these numbers have for base the centimetre as unit of length, and the day as unit of time.

In relation to the diffusion of quantities of salt, older experiments of Graham, and Marignac's comprehensive experiments especially, have taught us that the parts of the mixture essentially effect one another, so that the more diffusible of the two salts in the mixture diffuses still more quickly, and the other still more slowly, than when it alone is present. Also, from the experiments here discussed it follows, at the same time, that the distribution of each of the two salts, especially of the more quickly diffusing one, sensibly deviates from the laws of simple diffusion. So much more remarkable is it that the distribution of the mixture as a whole, as shown by the series under III., so closely conforms to those laws.

There are two experiments of this kind specially important. The first refers to a mixture of chloride of potassium and sulphate of soda, the second to a mixture of chloride of sodium and sulphate of potass. Both proceed in almost the same way; and although Graham did not complete the analyses, it may yet be concluded from his statements that the upper layers contained chloride of potassium in the second experinent also.

Such cases of decomposition by diffusion, as Graham calls them, were already known from his older experiments. It is more correct to assume that the decompositions take place in the mixture before the diffusion, and that the latter only acts the part of a sieve which lets through more readily the one product than the other.-Kaiserliche Akademie der Wissenschaften in Wien, math.-naturw. Classe, 1879, No. 3, pp. 24-27.

ON THE SPECTRUM OF OXYGEN, AND ON THE ELECTRICAL LUMI-

NOUS PHENOMENA OF RAREFIED GASES IN TUBES WITH LIQUID

ELECTRODES. BY M. PAALZOW.

As a rule, in the examination of the electrical luminous phenoPhil. Mag. S. 5. Vol. 7. No. 43. April 1879. 2 A 
mena of rarefied gases, the electricity is conducted to the gas enclosed in a glass tube through metal wires fused into the tube. Since the metals are very likely to exert an influence upon the phenomena, I have tried the insertion of a liquid between the metal and the gas, in order, to some extent, to form liquid electrodes.

A glass tube twice bent at right angles contained in its wider parts fused-in platinum wires and concentrated sulphuric acid, the latter rising one centimetre above the wires. The tube was joined by fusion to a mercury air-pump, the drying-ressel of which was filled with solid phosphoric acid.

The gases contained in the tube and the pump having been so far rarefied that an induction-current could pass through, the platinum wires were connected with the poles of a Ruhmkorff inductorium, which, excited by four Bunsens, gave a striking-distance of 71 millims. and a deflection of 50 scale-divisions on a mirrorcompass. (A constant current of 0.00035 Siemens-Daniell unit gave, on the same compass, with the same spirals, a deflection of 100 scale-divisions. The value of the 50 scale-divisions of the momentary current, calculated from the duration of a vibration of the damped magnet and from its logarithmic decrement, amounted to 0.000013 S.-D. unit.)

The luminons phenomena observed in the tube under these circumstances are in general similar to those seen in tubes the wires of which are provided with metal disks.

The positive light starts from the bounding line of the surface of the liquid and the glass wall, and spreads, in narrower or wider strata (according to the strength of the pressure of the gas), to the vicinity of the negative liquid.

From the surface of the negative liquid itself there rises, at some distance from it, a slightly conic ring of light, similarly to the flame of a ring-shaped burner. The intensity of this ring diminishes from below upwards. The more the rarefaction increases, the more does this negative luminous cylinder lengthen, and the greater becomes its distance from the surface of the liquid. With the strongest rarefaction the luminous phenomena are almost the same at both poles. The negative light makes its appearance also in the narrow parts of the tube*. When the entire tube is inclined so that the liquid surfaces are bounded by ellipses, the positive light emanates from the highest part of the boundary, the negative is most intense at the lowest point, but the entire ring of light remains parallel to the sides of the tube.

The magnetic deflection of the positive and the negative light is the same as that in the before-mentioned tubes with metal disks.

The whole tube is besides filled with diffused glittering light, which when nitrogen is present is greenish (according to Morren proceeding from the formation or decomposition of the compound $\mathrm{NO}_{3}+2 \mathrm{SO}_{3}$ ); without nitrogen it is bluish, and then perhaps arises from the vapour of sulphuric acid. This light can be insulated ; and then it gives a continuous spectrum.

The entire luminous process is accompanied by decomposition of

* Goldstein, Berl. Monatsber. May 1876, p. 279. 
sulphuric acid ; from all parts of the immersed platinum wires gasbubbles are seen to rise. The positive wire furnishes oxygen, the positive liquid surface hydrogen; and it is the reverse at the negative side. Various other examples can be cited in proof that a dividing surface between a liquid and a gas may be regarded as an electrode. This view receives especial confirmation from the phenomena of occlusion*. If, namely, the current has passed through for a long time, one induction-shock in the same direction furnishes distinct gas-bubbles; if now the current be reversed, 7-9 induction-shocks will be necessary at the electrode charged with oxygen before the gas-bubbles are observed, while at that charged with hydrogen certainly $15-17$ will be required.

When the electrolytic process was continued during a whole week, predominantly oxygen only was obtained in the tube. Primarily, however, both oxygen and hydrogen are always separated; but the latter finally precipitates sulphur from the sulphuric acid, which at first makes the liquid thick, and then settles to the bottom.

In order to decipher and explain the complex spectrum, I was obliged to carry out two new operations--to produce a pure oxygenspectrum, and to determine the conductivity of the pure gases oxygen, hydrogen, nitrogen. I permit myself here only to report upon the oxygen-spectrum, reserving for subsequent communications the conductivity of the gases mentioned.

In the tube there might be contained nitrogen, hydrogen, oxygen, mercury-vapour. On the spectrum of oxygen the most diverse results have been given by Plücker (Pogg. Ann. cvii. p. 497), Wüllner (Pogg. Ann. exxxv. p. 377), Salet (Ann. d. Chim. [4] xxviii. p. 5), Vogel (Pogg. Ann. cxlvi. p. 569), Huggins (Phil. Trans. cliv. p. 139), Plücker and Hittorff (Phil. Trans. clv. p. 1), and Schuster (Proc. Roy. Soc. xxvii. p. 383).

The tubes for examination I filled with oxygen :--(1) after the method previously described, by decomposition of the concentrated sulphuric acid by the induction-current, when finally oxygen was almost solely evolved; (2) by fusing to the experiment-tube a voltameter containing concentrated sulphuric acid, six Bunsen cells being employed for the decomposition ; (3) by heating chlorate of potass in a retort united directly to the tube by fusion.

I was at length obliged to abandon the use of a gasometer and any other drying-apparatus than that attached to the air-pump, containing solid phosphoric acid, since they never furnished pure results.

Tightening the stoppers and cocks with tallow, caoutchouc, or concentrated sulphuric acid gave the same results.

The filling and exhaustion of the vessels and pump were of course repeated until the phenomena became constant-most frequently from 40 to 50 times $\uparrow$.

I have always found only one oxygen-spectrum, consisting of

* Helmholtz, Pogg. Ann. cl. p. 483.

† I made use of the appearance of the intensely green Huorescence-light of glass as a sign that the exhaustion of the tubes was as complete as possible. 
five bright lines*. I determined their positions by means of a Steinheil's apparatus with a prism, according to a scale, in which

$$
\begin{aligned}
& \begin{array}{llllll}
\text { C } & \text { D } & \text { E } & b & \text { F } & \text { G }
\end{array} \\
& \text { are situated at } \ldots .35|50| 69.5|74| 87 \mid 117
\end{aligned}
$$

If the five lines from the red onwards be designated by $\mathrm{O}_{\alpha}, \mathrm{O}_{\beta}, \mathrm{O}_{\gamma}$, $\mathrm{O}_{\delta}, \mathrm{O}_{e}$, we have

$$
\begin{aligned}
& \begin{array}{lllll}
\mathrm{O}_{\alpha} & \mathrm{O}_{\beta} & \mathrm{O}_{\gamma} & \mathrm{O}_{\delta} & \mathrm{O}_{e}
\end{array}
\end{aligned}
$$

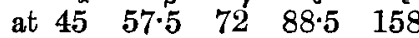

With the aid of the spectral apparatus with four prisms lent me by M. Kirchhoff, I determined the lines according to Kirchhoff's plate, according to which

$$
\begin{array}{rcccc}
\mathrm{O}_{a} & \mathrm{O}_{\beta} & \mathrm{O}_{\gamma} & \mathrm{O}_{\delta} & \mathrm{O}_{e} \\
\text { are situated at } 935 & 1231 & 1625 & 2164 & 2489
\end{array}
$$

From comparison of these Kirchhoff's lines with Ångström's plates the wave-lengths of

$$
\begin{array}{ccccc}
\mathrm{O}_{\alpha} & \mathrm{O}_{\boldsymbol{\beta}} & \mathrm{O}_{\gamma} & \mathrm{O}_{\delta} & \mathrm{O}_{\varepsilon} \\
\text { are } 602 & \mathbf{5 5 8 \cdot 2} & \mathbf{5 1 9} & 481 & \mathbf{4 5 3}
\end{array}
$$

The intensity of $\mathrm{O}_{\gamma}$ is the greatest; then follow $\mathrm{O}_{\beta}$ and $\mathrm{O}_{\delta}$, and last $\mathrm{O}_{\varepsilon}$ and $\mathrm{O}_{\alpha}$. The lines are sharp towards the red end of the spectrum, fading towards the violet. Their wave-lengths agree best with those given by M. Vogel; only he did not observe $\mathrm{O}_{\alpha}$, perhaps because the pressure of the gas was not sufficient. Plïcker's lines $\mathrm{O}_{\alpha}$ and $\mathrm{O}_{\delta}$ are probably mercury-lines.

Contrary to Mr. Schuster's latest statement, I find the spectrum of pure oxygen equally at both poles. I find this identity in the hydrogen also, and in the nitrogen only an intensifying of two of its lines ( 95 and 125 of the first scale). If the gases are not pure, other lines may come in at the negative pole, because the ponderable mass is thrown off at that pole.

I have intentionally employed only simple induction-currents, because with the rapid and violent discharge of a Leyden jar portions of the electrodes and glass sides may be carried along in the discharge-current, which with the quiet discharge of the simple induction-current remain undisturbed in their places. At all events I hold that the question whether there is a plurality of spectra of a pure gas is still an open one, and am inclined rather to ascribe to each simple gas one spectrum only. With oxygen, which I have pursued within variations of pressure from 200 millims. to the most extreme rarefaction, I have never seen any other lines than the five named ; and these, brightest at 2 millims. pressure, diminish in brightness in both directions from that point, so that at very inconsiderable and at high pressures only a glimmer of light is visible, which I would not call a continuous, but much rather an indistinct spectrum.-Monatsbericht der königlich preussichen Akademie der Wissenschaften zu Berlin, Sept. \& Oct. 1878, pp. 705-709.

* Between $\mathrm{O}_{\beta}$ and $\mathrm{O}_{\gamma}$ three, before $\mathrm{O}_{\alpha}$ four, and behind $\mathrm{O}_{\epsilon}$ one broad streak of light are to be seen, but so faint that they can never be confounded with the five lines; besides, they are quite destitute of a sharp margin, and cannot be analyzed with the four-prism apparatus. 